\title{
TINGKAH LAKU MAKAN LUTUNG JAWA Trachypithecus auratus DI KAWASAN PANCURAN 7 BATURADEN GUNUNG SLAMET JAWA TENGAH
}

\author{
DWi Eliana, ERIE Kolya NASUTION, INDARMAWAN
}

Fakultas Biologi, Universitas Jenderal Soedirman, Jalan dr. Suparno 63 Purwokerto 53122

\section{A B S T R A C T}

Javan Langur (Trachypithecus auratus) has an important ecological role in conserving the forest as their habitat by spreading seeds of fruits of their food. They are also responsible for the pattern of the plant diversity and forest regeneration as their habitat. Unfortunately, Javan Langur has been listed on Appendix II of CITES and categorized as vulnerable by the IUCN. Pancuran 7 Baturaden on the Mount Slamet slope is one of the few Javan Langur habitats in Java. Information on the Javan Langur in this area was inadequate. Therefore this study was aimed to get information on the type of food and the feeding behavior of Javan Langur, particularly in Pancuran 7 Baturaden. This study used a survey method, and the Animal Scan sampling technique was applied. The variables observed were sex ratio, population size, eating position, eating process, feeding locations, feeding duration, including the food type of the Javan Langur. Observed data for each variable were analyzed descriptively as percentages, and the results showed the Javan Langur were eating by sitting and standing, were marking trees to feed, were using hands and mouth to eat, were eating leaves and fruit, were eating on the trees and bushes. There were nine plant species as their food variety, while Matoa fruit and leave (Pometia pinnata) were their preferred foods.

KEY WORDS: Javan Langur, feeding behavior, Baturraden, Mount Slamet

Penulis korespondensi: DwI ELIANA | email: deliana20@gmail.com

\section{PENDAHULUAN}

Lutung Jawa (Trachypithecus auratus) merupakan salah satu satwa yang dilindungi. Berdasarkan IUCN, Lutung Jawa termasuk dalam status Vulnerable (terancam punah) dan terdaftar pada Appendix II (tidak boleh diperdagangkan) dalam CITES. Hal tersebut karena populasi Lutung Jawa sudah sedikit. Penurunan populasi Lutung Jawa disebabkan oleh penurunan kuantitas dan kualitas habitat, tingkat perburuan liar, konversi lahan, dan perdagangan satwa liar (Nijman \& Supriatna, 2008). Lutung Jawa merupakan hewan pemakan daun, buah-buahan dan biji-bijian (Kool, 1993). Lutung Jawa tinggal di hutan bakau, hutan dataran rendah, hutan dataran tinggi, hutan primer, hutan sekunder, perkebunan dan hutan tanaman (Supriatna dan Wahyono, 2000).

Tajuk hutan yang tumbuh secara vertikal di daerah hutan hujan tropis menjadi penyedia pakan yang sangat penting bagi lutung (Rijksen, 1978). Salah satu upaya untuk mempertahankan keberadaan lutung Jawa adalah dengan menjaga kualitas dan kuantitas habitatnya. Menurut Bismark (1993), data tentang tumbuhan sebagai penyedia pakan dan pendukung tingkah laku makan sangat penting untuk dijadikan acuan dalam pengelolaan konservasi dan habitat lutung di masa depan.

Hutan Gunung Slamet merupakan batas peralihan antara hutan Barat dan Timur pulau Jawa yang berdasarkan tumbuhan dan satwa penyusunnya membawa sifat khas keanekaragaman hayatinya (Rustiami et al., 2005). Sulistyadi (2013) menyatakan bahwa Lutung Jawa memegang peranan penting dalam ekosistem hutan di Gunung Slamet. Kawasan Pancuran 7 Baturaden terletak di Lereng Selatan Gunung Slamet dan merupakan habitat Lutung Jawa. Data mengenai kehidupan Lutung Jawa di Lereng
Selatan Gunung Slamet, terutama jenis pakan dan tingkah laku makan perlu diungkap melalui penelitian sebagai data pendukung dalam upaya konservasi dan pengelolaan kawasan hutan Gunung Slamet. Tujuan dari penelitian ini adalah untuk mendapatkan informasi tentang: jenis pakan yang paling banyak dikunjungi Lutung Jawa di Kawasan Pancuran 7 Baturaden Gunung Slamet, dan tingkah laku makan Lutung Jawa yang ada di Kawasan Pancuran 7 Baturaden Gunung Slamet.

Manfaat penelitian ini yaitu dapat memberikan informasi tentang jenis pakan yang paling banyak dikunjungi dan tingkah laku makan Lutung Jawa di Kawasan Pancuran 7, Baturaden Gunung Slamet.

\section{MET ODE PENELITIAN}

Metode yang digunakan dalam penelitian adalah Metode Survei dengan teknik Scan Animal Sampling yaitu dengan mencatat tingkah laku makan pada beberapa individu dalam waktu yang bersamaan setiap 15 menit sekali (Martin \& Bateson, 1986). Pengamatan sampling yang diambil meliputi posisi makan, cara makan, lokasi makan, durasi makan, cara mencari pakan, bagian tumbuhan pakan, serta jenis pakan Lutung Jawa. Waktu pengamatan dibagi menjadi tiga waktu yaitu pagi hari pukul 06.00-10.00 WIB, siang hari pukul 10.00-14.00 WIB dan sore hari pukul 14.00-18.00 WIB (Pratiwi, 2008).

Survei lokasi dengan cara menjelajahi kawasan Pancuran 7 Baturaden Gunung Slamet yang diduga terdapat lutung yaitu ruang jelajahnya seputar lokasi wisata Pancuran 7 Baturaden turun ke perbukitan di bawahnya lalu memutar naik kembali ke daerah lokasi wisata ke Pancuran 7 Baturaden. Populasi lutung dan jenis kelamin dicatat. Faktor lingkungan yang diukur yaitu mengukur temperatur, kelembaban, dan ketinggian. Tingkah laku makan lutung dalam sebuah kelompok dicatat setiap 15 menit berupa posisi makan, cara makan, lokasi makan, durasi makan, cara mencari pakan, bagian tumbuhan pakan, dan jenis tumbuhan pakan. 
Pengumpulan data sekunder yang dikumpulkan meliputi peta lokasi penelitian dan gambaran umum lokasi penelitian lutung. Pengamatan juga dilakukan pada beberapa jenis satwa selain lutung untuk mengetahui satwa kompetitor lutung. Data yang diperoleh dari hasil pengamatan dianalisis secara deskriptif dalam bentuk persentasi durasi makan, jenis tumbuhan pakan, serta tingkah laku makan yang disajikan dalam bentuk tabel.

\section{HASIL DAN PEMBAHASAN}

Kawasan Pancuran 7 Baturraden merupakan hutan sekunder di Lereng Selatan Gunung Slamet yang berada pada ketinggian 700-800 mdpl (meter diatas permukaan laut). Kawasan ini merupakan daerah perbukitan yang cukup tinggi dan panjang, kecuraman berkisar antara $30^{\circ}$ dan $40^{\circ}$. Pada kawasan Pancuran 7 Baturraden dengan koordinat -7.309354 LS 109.214624 BT hingga -7.311317 LS, 109.215171 BT., dapat ditemukan berbagai jenis satwa, salah satunya adalah Lutung Jawa.

Selama penelitian, Lutung Jawa ditemukan pada area berupa vegetasi pohon tinggi dan vegetasi bawah yang terdegradasi. Menurut Sulistyadi (2012), mamal besar seperti Lutung Jawa di Gunung Slamet cenderung lebih menyukai habitat hutan alami (primer dan sekunder) dengan ketinggian yang sangat terkait dengan kondisi vegetasi dan kelerengan. Kawasan Pancuran 7 Baturraden merupakan kawasan hutan alami sekunder yang sudah banyak ditanami vegetasi pohon dari daerah lain.

Penelitian dilakukan pada musim hujan dengan temperatur rata-rata pagi hari $\pm 22,9^{\circ} \mathrm{C}\left(20-25^{\circ} \mathrm{C}\right)$, siang hari $\pm 27^{\circ} \mathrm{C}\left(25-29^{\circ} \mathrm{C}\right)$, dan sore hari $\pm 26,5^{\circ} \mathrm{C}$ $\left(25-28^{\circ} \mathrm{C}\right)$. Angka kelembapan pada pagi hari yaitu sebesar $\pm 77,5 \%$ (75-79\%), siang hari yaitu sebesar \pm $72 \%(68-74 \%)$, serta pada sore hari sebesar $\pm 74,6 \%$ (74-77\%). Rentang temperatur dan kelembapan dari yang terendah sampai tertinggi yaitu $22,9-27^{\circ} \mathrm{C}$ dan $72-77,5 \%$. Keadaan temperatur dan kelembapan tersebut cukup ideal untuk tingkah laku makan Lutung Jawa. Menurut Nadler et al. (2003) lutung cenderung makan dan berkumpul pada temperatur $10-30^{\circ} \mathrm{C}$.

Selama penelitian diperoleh data sebanyak sembilan jenis tumbuhan pakan yang dikunjungi oleh Lutung Jawa. Jenis pakan tersebut terdiri atas delapan jenis pohon dan satu jenis semak. Pohon pakan tersebut yaitu Matoa (Pometia pinnata), Antap (Sterculia subpeltata), Ara (Ficus fistulosa), Rasamala (Altingia excelsea), Cempaga (Dysoxylum densiflorum), Sengon (Albizia chinensis), Pisang Kele (Musa sp.), dan Mara (Macaranga tanarius). Sementara itu, jenis semak yang disukai Lutung Jawa adalah Kemadu (Laportea sinuata). Tumbuhan pakan yang banyak dikunjungi Lutung Jawa yaitu pohon Matoa (35,6\%) dan Antap (29,7\%), sedangkan jenis pakan yang lain masing-masing nilainya dibawah 10\% (Tabel 1).

Matoa merupakan tumbuhan pakan yang paling banyak dikunjungi oleh Lutung Jawa dibanding tumbuhan pakan lain. Matoa merupakan pohon dengan ukuran batang yang besar, cabang banyak, ranting banyak dan besar, berkanopi luas serta letaknya dekat dengan pepohonan lain. Pohon Matoa tersebar sepanjang perbukitan di kawasan penelitian. Jumlah pohon Matoa di wilayah penelitian 30 buah dan cukup untuk mendukung kehidupan lutung. Pohon Matoa sering dikunjungi lutung karena banyak buah serta daun-daun muda yang berukuran kecil dan mudah dimakan lutung.

Pohon Antap merupakan sumber pakan dominan kedua. Ciri-ciri Pohon Antap yaitu memiliki ukuran pohon yang besar, tinggi, percabangan banyak, ranting kuat, daun berukuran kecil dan tidak berbuah. Jumlah Pohon Antap di area penelitian adalah 11 pohon tersebar di area penelitian. Pohon Antap disukai Lutung Jawa karena memiliki daun yang berukuran kecil sehingga mudah untuk dimakan.

Tingkat kesukaan Lutung Jawa terhadap daun muda lebih besar $(51,9 \%)$ dibandingkan dengan buah (48,1\%) (Tabel 1). Menurut Prayogo (2006) lutung lebih suka daun muda dibanding daun tua karena strukturnya yang lunak dan warna yang cerah, serta berdasarkan kandungannya daun muda lebih banyak mengandung nutrisi dibandingkan dengan daun tua.

Lutung merupakan primata yang bersifat folivorus (pemakan daun) oleh karena itu lutung pada penelitian lebih banyak makan daun dibanding makan buah. Lutung sebagai pemakan daun yang kaya akan serat masih memungkinkan makan buah karena didukung oleh sistem pencernaan yang sangat panjang. Selain buah-buahan, Lutung juga makan telur-telur burung pada kondisi tertentu (Rijksen, 1978). Lutung Jawa memakan buah-buahan karena rasa yang manis dan struktur yang lunak, Kool (1993) menambahkan bahwa kandungan tanin dan fenol dalam buah membantu pencernaan.

Lutung Jawa di Kawasan Pancuran 7 Baturaden tercatat 30 individu yang terbagi dalam 5 kelompok di 4 tempat yang berbeda (Tabel 2). Masing-masing kelompok terdiri dari 2-15 individu. Hal tersebut mendekati pernyataan Cannon (2009) bahwa secara alami kelompok Lutung Jawa terdiri dari 6-23 individu dengan satu jantan sebagai pemimpin, beberapa betina dewasa, anak, dan bayi. Ukuran kelompok lutung juga dipengaruhi oleh faktor iklim dan musim yang terkait dengan ketersediaan pakan. Besarnya jumlah individu dalam kelompok Lutung Jawa di Kawasan Pancuran 7 Baturaden dipengaruhi oleh kelimpahan pakan yang tersedia dan kemampuan adaptasi yang baik terhadap aktivitas manusia.

Lutung Jawa banyak ditemukan dekat dengan sumber pakan dan sumber mata air. Menurut Ayunin (2016), diantara faktor yang dapat mempengaruhi keberadaan lutung yaitu keberadaan sumber pakan, karakteristik fisik pohon, karakteristik habitat, topografi keragaman vegetasi, kerapatan pohon pakan, kerapatan vegetasi tinggi, dan ukuran pohon. Lokasi penelitian merupakan daerah dengan sumber pakan dan sumber mata air yang melimpah sehingga mendukung kehidupan Lutung Jawa. 
Tabel 1. Presentasi Species Tumbuhan Pakan Lutung

\begin{tabular}{|c|c|c|c|c|c|c|}
\hline \multirow{2}{*}{ No } & \multirow{2}{*}{ Nama Pakan } & \multirow{2}{*}{ Nama Ilmiah } & \multirow{2}{*}{$\begin{array}{r}\text { Kelimpahan } \\
\text { (individu) }\end{array}$} & \multicolumn{2}{|c|}{ Bagian Pakan } & \multirow{2}{*}{ Tingkat Kesukaan (\%) } \\
\hline & & & & Buah (\%) & $\overline{\text { Daun (\%) }}$ & \\
\hline 1 & Matoa & Pometia pinnata & 30 & 24,3 & 11,3 & 35,6 \\
\hline 2 & Antap & Sterculia subpeltata & 11 & 0 & 29,7 & 29,7 \\
\hline 3 & Ara & Ficus fistulosa & 14 & 6,4 & 3,4 & 9,8 \\
\hline 4 & Rasamala & Altingia excelsea & 5 & 5,9 & 1 & 6,9 \\
\hline 5 & Cempaga & Dysoxylum densiflorum & 15 & 3,8 & 1,2 & 5 \\
\hline 6 & Sengon & Albizia chinensis & 10 & 0 & 4 & 4 \\
\hline 7 & Kemadu & Laportea sinuata & $>100$ & 3 & 0 & 3 \\
\hline 8 & Pisang Kele & Musa sp. & 30 & 3 & 0 & 3 \\
\hline 9 & Mara & Macaranga tanarius & $>100$ & 1,7 & 1,3 & 3 \\
\hline & Jumlah & & & 48,1 & 51,9 & 100 \\
\hline
\end{tabular}

Tabel 2. Populasi Lutung di Kawasan Pancuran 7 Baturaden

\begin{tabular}{|c|c|c|c|c|c|c|c|}
\hline \multirow{3}{*}{ Kelompok } & \multicolumn{4}{|c|}{ Jumlah } & \multirow{3}{*}{ Anakan } & \multirow{3}{*}{ Total } & \multirow{3}{*}{ Letak } \\
\hline & \multicolumn{2}{|c|}{ Dewasa } & \multicolumn{2}{|c|}{ Remaja } & & & \\
\hline & Jantan & Betina & Jantan & Betina & & & \\
\hline 1 & 1 & 1 & - & - & - & 2 & Ujung Perbukitan sebelah barat Pancuran 7 Baturaden \\
\hline 2 & 5 & 2 & 3 & 2 & 3 & 15 & Kawasan Utama Pancuran 7 \\
\hline 3 & 2 & 1 & 1 & - & 1 & 5 & Area aliran sungai kali akar \\
\hline 4 & 1 & 1 & - & - & - & 2 & Bawah kawasan Pancuran 7 bagian timur \\
\hline 5 & 2 & 1 & 1 & 1 & 1 & 6 & Bawah kawasan Pancuran 7 bagian timur \\
\hline Jumlah & & & & & & 30 & \\
\hline
\end{tabular}

Hasil penelitian tingkah laku makan Lutung Jawa disajikan pada tabel 3. Hasil pengamatan tingkah laku makan lutung menunjukan posisi makan dengan duduk dan berdiri. Posisi makan dengan bergelantungan tidak dijumpai karena sulit dilakukan saat proses mendapatkan makanan hingga memasukannya ke dalam mulut. Posisi berdiri hanya di temukan pada jantan dewasa sambil melakukan pengawasan dan perlindungan pada kelompoknya saat ada kompetitor berupa monyet ekor panjang (Macaca fascicularis), yang berada tidak jauh dari pohon pakan. Posisi duduk merupakan posisi yang dominan karena memungkinkan lutung dalam menjaga keseimbangan. Hal ini dilakukan dengan cara mengaitkan kaki pada dahan pohon sehingga memudahkan kedua tangan digunakan sepenuhnya untuk makan. Hal ini sesuai dengan penelitian Nurwulan (2002) yang menyebutkan bahwa posisi yang sering dilakukan lutung ketika makan adalah duduk di batang pohon dengan posisi tangan kiri memegang cabang pohon dan tangan kanan digunakan untuk memasukkan makanan ke dalam mulutnya.

Hasil pengamatan menunjukan Lutung Jawa makan dengan menggunakan tangan dan mulut. Tangan kanan digunakan untuk memetik daun dan memasukan makanan ke dalam mulut. Tangan kanan dan kiri digunakan secara bersamaan ketika memakan buah. Selain menggunakan tangan, Lutung Jawa juga menggunakan giginya untuk membelah buah yang berkulit keras. Menurut Prayogo (2006) lutung mengambil makanan dengan cara diambil secara langsung menggunakan mulut atau dengan cara memetiknya terlebih dahulu lalu dimasukkan ke dalam mulut. Lokasi makan Lutung Jawa sebagian besar dilakukan di pohon (98,9\%). Lokasi makan lutung di pohon sangat memungkinkan lutung untuk melakukan perpindahan dari satu pohon pakan ke pohon pakan lain. Menurut Sulistyadi (2012) hutan dengan pohon yang banyak dahannya memudahkan lutung dalam melakukan berbagai tingkah laku. Supriatna dan Wahyono (2000) juga menjelaskan bahwa lutung sebagai satwa folivorus (pemakan daun), menghabiskan lebih banyak waktunya di atas pohon (arboreal).

Tingkah laku makan di semak sangat sedikit $(0,10)$, menunjukkan bahwa Lutung Jawa kesulitan mendapatkan posisi makan yang nyaman di semak. Lutung Jawa tidak ditemui makan di tanah, karena jenis pakan yang disukai adalah daun muda dan buah yang berada diatas pohon. Selain itu tingkah laku makan di tanah tidak menguntungkan bagi keselamatan Lutung Jawa dari kompetitor dan ancaman satwa lain.

Tabel 3. Tingkah Laku Makan Lutung Jawa

\begin{tabular}{|c|c|c|c|}
\hline \multicolumn{3}{|c|}{ No Tingkah Laku Makan } & Persentasi (\%) \\
\hline \multirow[t]{3}{*}{1} & Posisi Makan & Duduk & 99,2 \\
\hline & & Berdiri & 0,80 \\
\hline & & Gelantungan & 0 \\
\hline \multirow[t]{2}{*}{2} & Cara Makan & Gigit Langsung & 0 \\
\hline & & Tangan & 100 \\
\hline \multirow[t]{3}{*}{3} & Lokasi Makan & Pohon & 98,90 \\
\hline & & Semak & 0,10 \\
\hline & & Tanah & 0 \\
\hline \multirow[t]{2}{*}{4} & Cara Mencari Makan & Mencari & 0 \\
\hline & & Menandai & $100 \%$ \\
\hline
\end{tabular}

Lutung Jawa mendapatkan pakan dengan cara menandai. Proses menandai dilakukan oleh pejantan sebagai pemimpin kelompok. Jika sumber pakan habis, lutung jantan mencari dan menandai sumber pakan yang lain. Tingkah laku menandai dicirikan dengan menghabiskan terlebih dahulu pakan sebelum berpindah ke pohon pakan yang lain. 
Tabel 4. Persentasi Pewaktuan Makan Tiap Jenis Kelamin Lutung Jawa

\begin{tabular}{clcccc}
\hline \multirow{2}{*}{ No } & \multirow{2}{*}{ Individu } & Pagi & Durasi Makan (\%) & \multicolumn{2}{c}{$\begin{array}{c}\text { Durasi Makan } \\
\text { Harian } \pm(\%)\end{array}$} \\
\cline { 3 - 5 } 1 & Jantan dewasa & 0,11 & Siang & Sore & 33 \\
2 & Betina dewasa & 0,05 & 0,11 & 0,12 & 25 \\
3 & Remaja jantan & 0,07 & 0,11 & 0,10 & 24 \\
4 & Remaja betina & 0,02 & 0,09 & 0,08 & 16 \\
5 & Anakan & 0,01 & 0,07 & 0,07 & 2 \\
\hline & Jumlah & $\mathbf{2 4 , 6 3}$ & 0,01 & 0,00 & $\mathbf{1 0 0}$ \\
\hline
\end{tabular}

Berdasarkan pengamatan, Lutung Jawa makan dalam tiga periode yaitu pagi pukul 07.00-10.00, siang pukul 11.00-14.00, dan sore pukul 14.00-16.30 (Tabel 4). Pada rentang dua periode yaitu pukul 11.00-14.00 dan pukul 14.00-16.30 tidak terdapat jeda karena tingginya presentasi tingkah laku makan pada kedua periode yang dipengaruhi oleh pengalihan tingkah laku makan pada pagi hari. Hal tersebut berbeda dengan penelitian Ihsanu et al. (2014) yang menerangkan bahwa aktifitas makan Lutung Jawa terjadi pada pagi hari pukul 07.00-11.00, siang pukul 13.00-14.00, serta sore pukul 15.00-17.00 WIB, saat musim kemarau dengan lokasi penelitian di Situ Sangiang Taman Nasional Gunung Ciremai, Kabupaten Majalengka, Provinsi Jawa Barat. Perbedaan tersebut dipengaruhi karena adanya perbedaan karakteristik iklim pada lokasi penelitian. Penelitian Lutung Jawa di kawasan Pancuran 7 Baturaden di lakukan saat musim hujan dengan kelembapan yang cukup tinggi (72-74,6\%), frekuensi hujan yang cukup banyak, dan kuantitas penyinaran panas matahari ke area tempat penelitian.

Persentasi pewaktuan makan per jenis kelamin menunjukan bahwa pewaktuan makan terjadi pada pagi sebesar 24,63\%, siang sebesar 38,38\%, serta sore sebesar 36,99\%. Hal tersebut berbeda dengan pernyataan Sulistyadi (2013) yang menyatakan bahwa lutung melakukan tingkah laku pada pagi hari dengan persentasi tertinggi adalah makan yaitu sebesar $54,73 \%$ yang dilakukan pada bulan Mei-Juni 2012 menunjukan musim kemarau. Perbedaan dominansi waktu makan tersebut dipengaruhi akibat perbedaan cuaca dan iklim yang terdapat di masingmasing tempat penelitian. Cuaca dan iklim pada kawasan Pancuran 7 Baturaden saat dilakukan penelitian menunjukan kondisi yang cukup mendung dengan banyaknya awan gelap sehingga kuantitas hujan pun menunjukan frekuensi yang tinggi.

Faktor yang berpengaruh pada dominasi waktu makan pada siang hari $(38,38 \%)$ dan sore hari $(36,99 \%)$ yaitu pengaruh cuaca dingin sehingga menunda tingkah laku makan pada pagi hari. Kebutuhan energi di malam hari di suplai dari banyaknya konsumi pakan pada sore hari. Tingkah laku makan Lutung Jawa saat siang hari dipengaruhi oleh redup atau terangnya cahaya matahari yang sampai pada permukaan kanopi dan tempat Lutung Jawa berada. Lutung Jawa lebih memilih makan ketika cahaya matahari sedang bersinar terang yang ditunjukan dengan cara naik ke atas permukaan kanopi paling tinggi lalu turun ke strata pohon lebih rendah ketika cahaya matahari redup. Pewaktuan makan harian per jenis kelamin menunjukan, jantan dewasa dengan pewaktuan makan paling tinggi (33\%) sedangkan anakan lutung menunjukan angka pewaktuan makan yang sangat kecil. Pewaktuan makan yang diperoleh berbeda dengan penelitian Kool (1993) dan Richardson (2005) yang menyatakan bahwa proporsi makan lutung jantan dewasa lebih sedikit dibandingkan dengan betina dan anakan. Perbedaan tersebut dipengaruhi oleh rendahnya perjumpaan betina dan anakan yang di sebabkan banyaknya cabang-cabang pohon pakan yang menutupi. Anakan yang sering dijumpai adalah anakan masih bayi yang selalu berada dalam gendongan induknya.

Lokasi penelitian merupakan hutan sekunder dengan sumber pakan yang melimpah. Oleh karena itu banyak terdapat satwa lain meliputi Rek-rekan (Presbytis fredericae), monyet ekor panjang (Macaca fascicularis), tupai (Tupaia javanica), elang jawa (Spizaetus bartelsi) dan elang brontok (Spizaetus cirrhatus). Satwa yang menjadi kompetitor langsung dengan Lutung Jawa adalah monyet ekor panjang dan rek-rekan. Monyet ekor panjang adalah kompetitor Lutung Jawa yang paling sering dijumpai. Ciri-ciri kedatangan monyet ekor panjang yaitu Lutung Jawa mengeluarkan suaranya. Lutung Jawa dan monyet ekor panjang yang dijumpai di lokasi penelitian hidup secara berdampingan. Hal tersebut diduga karena ketersediaan pakan yang cukup melimpah sehingga Lutung Jawa dan monyet ekor panjang tidak saling mengganggu dalam mendapatkan makanan. Menurut Iqbal (2013), Lutung Jawa lebih memilih menghindar bila berhadapan dengan monyet ekor panjang terutama ketika makan.

\section{KESIMPULAN DAN SARAN}

Species pohon di Pancuran 7 Baturraden yang lebih dipilih untuk dikunjungi oleh lutung Jawa adalah Klengsar (Pometia pinnata) dan Antap (Sterculia subpeltata). Lutung Jawa melakukan aktivitas makan cenderung dengan cara duduk dan berdiri menggunakan tangan dengan memakan daun muda dan buah dalam tiga pewaktuan di pohon dan semak, serta dengan menandai pohon pakan terlebih dahulu.

Saran yang dapat disampaikan dari hasil penelitian ini adalah perlunya dilakukan reboisasi kawasan Pancuran 7 Baturraden dengan pohon Klengsar dan Antab sebagai pohon sumber pakan lutung Jawa dan perlindungannya dari berbagai aktivitas manusia di Kawasan Pancuran 7 Baturaden. 


\section{DAFT AR REFERENSI}

Ayunin Q, Pudyatmoko S, Imron MA. 2016. Seleksi habitat Lutung Jawa (Trachypithecus Auratus E. Geoffroy Saint-Hilaire, 1812) di Taman Nasional Gunung Merapi. Jurnal Penelitian Hutan dan Konservasi Alam 11(3):261-279.

Bismark M. 1993. Ekologi Makan Primata. Program Studi Pengelolaan Satwa Liar. Pasca Sarjana Universitas Gadjah Mada. Yogyakarta.

Cannon WA, Vos. 2009. Trachypithecus auratus [Internet]. Michigan: Animal Diversity Web: [cited 2015 December 11]. Available from:http://animaldiversity.org/accounts/Trachypithecus_aur atus/

Ihsanu IA, Setiawan A, Rustiati EL. 2014. Studi perilaku makan dan analisis vegetasi pakan Lutung Jawa (Trachypitecus auratus) di Taman Nasional Gunung Cermai. Jurnal Sylva Lestari 1(1):1722.

Kool KM. 1993. The diet and feeding behaviour of the silver leaf monkey (Trachypithecus auratus condaicus) in Indonesia. International Journal of Primatology 14(5):667-700.

Martin P, Bateson P. 1986. Research Design. Measuring Behavior: $25-55$.

Nadler T, Momberg F, Dang NX, Lormee N. 2003. Vietnam primates conservation review part II: leaf monkeys. Hanoi: Frankfurt Zoological Society and Fauna \& Flora International-Vietnam Programme; [cited 2016 March 13]. Available from: http://fauna-flora.org.

Nijman V, Supriatna J. 2008. Trachypithecus auratus. IUCN Red List of Threatened Species 2008: e.T22034A9348260. http://dx.doi.org/10.2305/IUCN.UK.2008.RLTS.T22034A9348 260.en [cited 2015 December 10]. Available from: http://iucnredlist.org/details/22034/0.
Nurwulan N. 2002. Pola Pemberian pakan Lutung Perak Kalimantan (Trachypithecus villosus) di Taman Margasatwa Ragunan [Laporan Magang]. [Bogor]: Fakultas Peternakan, Institut Pertanian Bogor.

Pratiwi AN. 2008. Aktivitas Pola Makan dan Pemilihan Pakan Pada Lutung Kelabu Betina (Trachypithecu cristatus, Raffles 1812) di Pusat Penyelamatan Satwa Gadog, Ciawi-Bogor [Skripsi]. [Bogor]: Program Studi Ilmu Nutrisi dan Makanan Ternak Fakultas Peternakan Institut Pertanian Bogor.

Prayogo H. 2006. Kajian tingkah laku dan analisis pakan Lutung Perak (Trachypithecus cristatus) di Pusat Primata Schmutzer Taman Margasatwa Ragunan [Tesis]. [Bogor]: Sekolah Pascasarjana, Institut Pertanian Bogor.

Richardson M. 2005. Javan langur (Trachypitecus auratus) [Internet]. ARKive: [cited 2015 December 10]. Available from: http://arkive.org/javan-langur/trachypithecus-auratus/.

Rijksen HD. 1978. A fieldstudy on sumatran orang utan (Pougo pygmaeus abelii Lesson 1827): ecology, behaviour and conservation [doctoral dissertation]. Veenman.

Rustiami H, Keim AP, Rugayah, Sunardi, Wardi. 2005. Keanekaragaman suku palem di Gunung Slamet Purwokerto. Laporan Teknik Bidang Botani Pusat Penelitian Biologi LIPI (1):573-577.

Sulistyadi E. 2012. Komunitas Mamalia Besar Gunung Slamet. In: Maryanto I, Noerdjito M, Partomihardjo T. Ekologi Gunung Slamet. Purwokerto: Universitas Jenderal Soedirman. p 121134

Supriatna J, Wahyono EH. 2000. Panduan lapangan primata Indonesia. Jakarta: Yayasan Obor Indonesia. p 332 